\title{
Toothache associated with ankylosing spondylitis
}

\author{
Jin-Kyu Kang ${ }^{1,2}$, Ji Won Ryu ${ }^{3 *}$ \\ ${ }^{1}$ Department of Orofacial Pain and Oral Medicine, Wonkwang University Daejeon Dental Hospital, Daejeon, Korea \\ ${ }^{2}$ Wonkwang Dental Research Institute, Wonkwang University, Iksan, Korea \\ ${ }^{3}$ Department of Oral Medicine, School of Dentistry, Chosun University, Gwangju, Korea
}

Ankylosing spondylitis (AS) is a chronic inflammatory joint disorder characterized by sacroiliitis, spondylitis and enthesitis. Patients suffering from AS may also have extra-articular symptoms, such as uveitis, bowl disease, heart, lung, skin, bone and kidney involvement, but vary widely in severity and prevalence. Facial manifestation of AS include eye involvement and temporomandibular joint involvement. In this study, a case of an AS that mimicked dental pain was presented.

Key Words: Ankylosing spondylitis, Orofacial pain, Toothache

(c) This is an open-access article distributed under the terms of the Creative Commons Attribution Non-Commercial License (http://creativecommons.org/licenses/by-nc/4.0) which permits unrestricted noncommercial use, distribution, and reproduction in any medium, provided the original work is properly cited.

\section{서 론}

강직성 척추염은 주로 엉덩이 천장 관절염(sacroiliitis), 척추 염(spondylitis), 부착부염(enthesitis) 등을 특징으로 하며, 전신 에 이환될 수 있는 면역 매개성 만성 염증성 질환이다. 일차적으 로 환축관절(axial joint)에 영향을 주며, 천장관절에 가장 많이 이환되며, 기타 호발하는 부위로는 척추, 말단관절, 인대나 힘줄 이 뼈에 붙는 부착부 등이 있다[1]. 관절 이외에 눈, 위장 관계, 폐, 심장, 신장, 전립선 등 다른 장기에도 침범할 수 있으며, 그 발생빈도와 증상의 심도는 매우 다양하다. 주로 나타나는 관절 외 증상은 포도막염, bowl disease, 만성 전립선염, 심장, 폐, 피 부, 뼈 및 신장의 침범 등으로 다양한 야기할 수 있다[2]. 구강안 면영역에서 강직성 척추염과 관련되어 나타날 수 있는 증상으로 temporomandibular joint (TMJ)의 이환[3,4], 눈의 포도막염과 관련되어 나타나는 안면통증 등이 있으며[2], 최근에는 치주염 과의 연관성이 보고되기도 했다[5-7]. 본 증례에서는 이전에 거
의 보고된 적이 없는 강직성 척추염과 관련된 치통의 증례를 보 고하고자 한다.

\section{증례보고}

25세 여성 환자가 우측 구치부 다수 치아의 통증을 주소로 원 광대학교 대전치과병원 구강내과에 내원하였다. 환자는 내원 4 일 전부터 통증이 나타나 점점 심해졌다고 하였고, 찌릿한 양 상의 통증이 오락가락하는 양상으로 한 시간에 수 회 나타나며 수 분에서 수십 분간 지속된다고 하였다. 밤에도 통증이 심하 여 잠을 잘 이루지 못할 정도라고 하였다. 시각통증척도(visual analog scale) 10 정도의 극심한 통증을 호소하였으며, 진료 중 에도 눈물을 흘리는 등 심한 고통을 호소하였다. 통증은 주로 상 악 우측 제 1,2 대구치 부위에서 나타나며, 비슷한 양상이 하악 우측 제 1,2 대구치 부위에서도 나타난다고 하였으나, 그 빈도 및 강도는 상악에 비해 덜하다고 하였다.

Received December 11, 2018; Revised December 18, 2018; Accepted December 19, 2018

Corresponding author: Ji Won Ryu, Department of Oral Medicine, School of Dentistry, Chosun University, 303 Pilmun-daero, Dong-gu, Gwangju 61452, Korea.

Tel: +82-62-220-3897, Fax: +82-62-234-2119, E-mail: dentian@chosun.ac.kr 


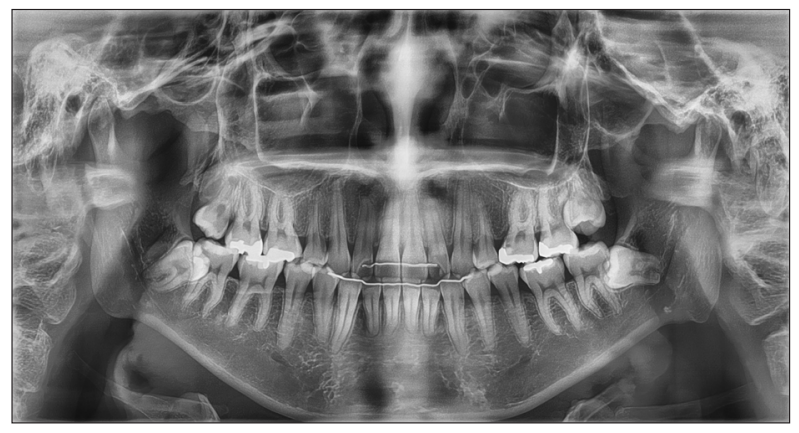

Fig. 1. Panoramic radiograph.

상악 우측 제 2 대구치의 육안관찰상 금 인레이 수복이 되어 있었으나 기타 특기할 이상소견은 관찰되지 않았고, 타진 및 동 요도 검사 시 정상 소견을 보였다. 치근단 방사선 사진 및 파노 라마 방사선 사진 상에서도 통증의 원인이 될 만한 소견은 관찰 되지 않았다(Fig. 1, 2)

신경병성 또는 신경혈관성 통증의 감별진단을 위하여 신 경과에 의뢰하였고, 환자는 신경과에서 강직성 척추염으 로 진단되어 센시발정(nortriptyline), 영풍칼리크리엔정 (kallidinogenase), 가바뉴로캡슐(pregabalin), 조피린장용정 (sulfasalazine)을 처방받아 복용한 후 치아의 통증이 완전히 소 실되었다.

\section{고 찰}

강직성 척추염은 원인불면의 만성 염증성 질환으로, 척주에 주로 이환된다. 전체 인구의 $1 \%$ 정도에서만 발생하는 질환으 로, 여성보다 남성에서 더 흔하며, 이환 관절의 경직감, 통증, 운 동 저하 등을 호소할 수 있다. 자주 이환되는 관절은 엉덩이, 어 깨, 무릎, 발, 손목 관절 등이다. 방사선사진상 이환된 골의 미 란 및 경화, 관절강의 pseudo-widening 및 골성 강직이 나타나 며, 섬유성 밴드에 의한 척추의 골화가 나타나 bamboo spine appearance를 보인다[1,2].

안면부 증상으로, 약 $40 \%$ 에서 눈의 anterior chamber에 염 증이 이환되어 눈의 통증, 발적, 광민감 등의 증상을 보일 수 있 다. 이는 ankylosing spondylitis와 포도막염의 유전적 연관성 때문(HLA-B27 antigen)인 것으로 생각된다[2,8]. 또한 연구에 따라 다르나 4\%-20\% 정도에서 $\mathrm{TMJ}$ 에 이환되기도 하며, 이 때 에는 개구 시 어려움 및 제한, 압통, 염발음, 교합 변화, 방사선 사진상 과두의 편평화 및 피질골 손상 등의 증상이 나타날 수 있 다[3,4].

이 증례는 상하악 다수의 구치부에서 나타난 심한 치통의 원 인으로 강직성 척추염이 의심되는 증례이다. 다수의 치아에서

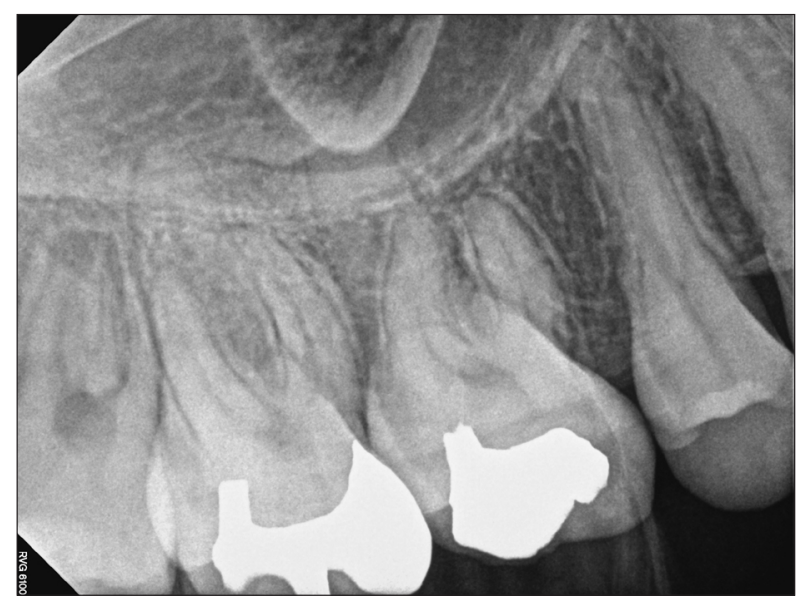

Fig. 2. Periapical radiograph on upper right molar region.

통증이 발생하였고, 통증의 강도나 양상이 일반적인 치통에 비 해서 매우 심하며, 방사선 사진상에서도 이상 소견이 관찰되지 않아 비치성 통증으로 생각되었다. 첫 내원 당시 치통을 감별하 기 위한 적절한 마취 검사나, 촉진 등의 검사가 이루어지지는 않 았으나, 일반적인 치성 기원의 통증 또는 근막통증이나 삼차신 경통과 같이 비교적 흔한 원인에 의해 나타나는 비치성 통증과 는 통증의 양상이 많이 달랐다. 비록 충분한 계속평가가 이루어 지지 않았고, 초진 시 적절한 임상 검사가 부족하기 때문에 치통 의 원인을 명확히 확진할 수는 없지만, 신경과 검사 결과 강직성 척추염 진단하에 처방된 약물이 치통을 효과적으로 감소시켰으 므로, 강직성 척추염과 동반되어 나타난 치통일 가능성이 있을 것으로 생각된다.

최근 Abbood 등[9]은 강직성 척추염 환자의 구강건강에 대한 연구를 보고하였다. 이 연구에서 구강궤양은 강직성 척추염 환 자 군이 대조군에 비해 유의성 있게 높은 결과를 보였으며, 치은 통증, 치아 동요, 치통 등의 증상은 전반적으로 대조군에 비해 다소 높은 수치를 보였으나 통계적 유의성은 없었다. 향후 치통, 구강궤양, 치주염 등의 다양한 종류의 구강질환과 강직성 척추 염의 연관성을 밝히기 위한 대규모의 연구가 필요하리라 생각 된다.

이 증례와 같이 강직성 척추염으로 인한 치통이 구치부에서 나타날 수 있다. 적절한 평가를 시행했음에도 원인이 불명확한 비치성 기원의 치통 환자에서 고려해야 될 원인질환 중 하나일 수 있으며, 만약 강직성 척추염이 의심될 경우 적절한 전문가에 게 의뢰하는 것이 필요하다.

\section{CONFLICTS OF INTEREST}

The authors declare that they have no competing 
interests.

\section{ORCID}

\author{
Jin-Kyu Kang \\ https://orcid.org/0000-0001-7668-7468 \\ Ji Won Ryu \\ https://orcid.org/0000-0002-5586-8195
}

\section{REFERENCES}

1. Smith JA. Update on ankylosing spondylitis: current concepts in pathogenesis. Curr Allergy Asthma Rep 2015;15:489. doi: 10.1007/s11882-014-0489-6.

2. El Maghraoui A. Extra-articular manifestations of ankylosing spondylitis: prevalence, characteristics and therapeutic implications. Eur J Intern Med 2011;22:554560. doi: 10.1016/j.ejim.2011.06.006.

3. Arora P, Amarnath J, Ravindra SV, Rallan M. Temporomandibular joint involvement in ankylosing spondylitis. BMJ Case Rep 2013;2013. doi: 10.1136/bcr2013-009386.

4. Helenius LM, Tervahartiala P, Helenius I, Al-Sukhun J, Kivisaari L, Suuronen R, Kautiainen H, Hallikainen D,
Lindqvist C, Leirisalo-Repo M. Clinical, radiographic and MRI findings of the temporomandibular joint in patients with different rheumatic diseases. Int J Oral Maxillofac Surg 2006;35:983-989. doi: 10.1016/j.ijom.2006.08.001.

5. Ratz T, Dean LE, Atzeni F, Reeks C, Macfarlane GJ, Macfarlane TV. A possible link between ankylosing spondylitis and periodontitis: a systematic review and meta-analysis. Rheumatology (Oxford) 2015;54:500-510. doi: 10.1093/rheumatology/keu356.

6. Kang EH, Lee JT, Lee HJ, Lee JY, Chang SH, Cho HJ, Choi BY, Ha YJ, Park KU, Song YW, Van Dyke TE, Lee YJ. Chronic periodontitis is associated with spinal dysmobility in patients with ankylosing spondylitis. J Periodontol 2015; 86:1303-1313. doi: 10.1902/jop.2015.150202.

7. Keller JJ, Kang JH, Lin HC. Association between ankylosing spondylitis and chronic periodontitis: a population-based study. Arthritis Rheum 2013;65:167-173. doi: 10.1002/ art.37746.

8. Bidad K, Gracey E, Hemington KS, Mapplebeck JCS, Davis $\mathrm{KD}$, Inman RD. Pain in ankylosing spondylitis: a neuroimmune collaboration. Nat Rev Rheumatol 2017;13:410420. doi: 10.1038/nrrheum.2017.92.

9. Abbood HM, Pathan E, Cherukara GP. The link between ankylosing spondylitis and oral health conditions: two nested case-control studies using data of the UK Biobank. J Appl Oral Sci 2018;27:e20180207. doi: 10.1590/16787757-2018-0207. 